\title{
Avaliações institucionais e de sistemas na formação de professores em Educação Física na América Latina
}

\author{
Institutional and systems evaluation in the teachers training in Physical Education \\ in Latin America
}

\author{
Wagner dos Santos* \\ Sayonara Cunha de Paula \\ Ronildo Stieg ${ }^{* * *}$
}

\section{Resumo}

Este artigo investiga como as avaliações institucionais e de sistemas são prescritas nos currículos dos cursos de formação de professores em Educação Física em oito países da América Latina. Utilizam-se como fontes 22 planos de disciplinas de avaliação educacional. A temática se apresenta em $19 \%$ e $23 \%$ dos planos, respectivamente. Sobre as avaliações institucionais, as disciplinas tematizam: definição, instrumentos, critérios, procedimentos e resultados, entendendo-as como importantes ferramentas coletivas. Já as avaliações de sistemas têm o intuito de apresentar as provas nacionais e internacionais, discutindo seus componentes e suas estruturas. Os dados revelam que os sistemas nacionais e internacionais de avaliação se diferem entre os países, assumindo diferentes nomenclaturas, períodos em que se aplicam, públicos-alvo e áreas abordadas, no entanto, é possível perceber um movimento de alinhamento do conhecimento a ser avaliado. Nessa direção, identifica-se a preocupação das disciplinas em possibilitar que o professor em formação conheça a estrutura dessas avaliações nos níveis nacional e internacional.

Palavras-chave: América Latina. Avaliação de sistemas. Avaliação institucional. Educação Física. Formação de professores.

\section{Abstract}

It investigates how the institutional and systems evaluation is prescribed in the curriculum of the training courses of Physical Education teachers in eight Latin American countries. It uses as sources 22 plans of disciplines of educational evaluation. The theme is presented in $19 \%$ and $23 \%$ of the plans, respectively. On the institutional evaluation, the disciplines discuss their definition, instruments, criterion, procedures and results, understanding it as an important collective tool. The system evaluations are intended to present the national and international evidence, discussing its components and structures. The data show that national and international systems of evaluation differ between countries assuming different nomenclatures, period in which they apply, target public and areas addressed, however it is possible to perceive a movement of alignment of the knowledge to be evaluated. In this direction, we identify the disciplines' concern in enabling the teacher in training to know the structure of these assessments at the national and international levels.

Keywords: Latin America. System evaluation. Institutional evaluation. Physical Education. Teacher training.

Recebido em 10/07/2018 - Aprovado em 27/09/2018

http://dx.doi.org/10.5335/rep.v26i1.8353

Doutor em Educação pela Universidade Federal do Espírito Santo. Professor do Programa de Pós-Graduação em Educação e em Educação Física da Universidade Federal do Espírito Santo. E-mail: wagnercefd@gmail.com

* Doutoranda em Educação Física na Universidade Federal do Espírito Santo. Professora da rede municipal de Cariacica, ES. E-mail: sayocpaula@hotmail.com

*** Doutorando em Educação Física na Universidade Federal do Espírito Santo. Professor da rede municipal de Cariacica, ES. E-mail: roni.stieg@gmail.com 


\section{Introdução}

A temática da avaliação é bastante recorrente no contexto escolar, abrangendo diferentes aspectos educacionais e abarcando três modalidades: aprendizagem, institucional e de sistemas. Constantemente, a avaliação tinha na aprendizagem dos alunos o centro de seu debate, no entanto, observamos uma mudança de foco para as outras modalidades, que, com o passar do tempo, foram ganhando destaque no cenário nacional e internacional.

Conceitualmente, a avaliação institucional pode ser definida como um processo que visa negociar patamares adequados de aprimoramento, com base nos problemas concretos vivenciados pela instituição de ensino, enquanto a avaliação de sistemas visa a um acompanhamento global das redes de ensino, com o objetivo de traçar séries históricas do desempenho dos sistemas que permitem verificar tendências ao longo do tempo, com a finalidade de reorientar políticas públicas (FREITAS, 2014).

A mudança de foco para essas modalidades está diretamente associada às reformas educativas da década de 1990 que impactaram a América Latina, levando os países a um investimento regional, nacional e internacional, no intuito de coletar dados e produzir informações que possibilitassem uma análise detalhada da realidade educacional e das dificuldades existentes (GAJARDO, 1999; OLIVEIRA, 2000).

Isso pode ser observado por meio das políticas educacionais e da criação de sistemas internacionais de avaliação que, em geral, realizam estudos comparativos em larga escala, tais como: International Association for the Evaluation of Educational Achievement (IEA), Programa de Promoção das Reformas Educacionais na América Latina e Caribe (PREAL), Organización para La Cooperación y El Desarrollo Económicos (OCDE) e Programme for International Student Assessment (Pisa).

Além dos mecanismos internacionais, Cerón e Cruz (2013) evidenciam que, especificamente na América Latina, nas últimas duas décadas, praticamente todos os países têm criado sistemas nacionais de avaliação da qualidade educacional, o que resultou na instalação de vários dispositivos para mensurar os resultados.

No entanto, é preciso ponderar que, ao falar de avaliação, não é possível considerar os programas educacionais sem pensar em alunos, professores, escolas, administração e sistema educacional como um todo indissolúvel. Conforme salientam Murillo e Román (2010), isso exige leitura e análise adequadas do sistema bem como dos atores da cena educacional, para fazer um julgamento de valor que alimente a tomada de decisão direcionada para melhorar a qualidade e os níveis de equidade da educação.

Nessa direção, Alavarse, Machado e Arcas (2017) pontuam que, ao avaliar os alunos, que também são avaliados na sala de aula pelos seus professores, é inegável que os docentes tenham acesso aos resultados das avaliações externas e os utilizem no desenvolvimento do seu trabalho nas escolas. Para os autores, os profissionais devem ser os principais usuários dos resultados das avaliações externas, e, para 
que essa possibilidade se efetive, é primordial que os professores as compreendam e principalmente as mobilizem como recurso pedagógico.

Especificamente na Educação Física, a articulação desse debate apresenta-se timidamente no Brasil e na América Latina. Stieg (2016), ao analisar o modo como as discussões sobre avaliação estão presentes nos referenciais teóricos das disciplinas específicas sobre o tema, dos cursos de licenciatura em Educação Física de oito universidades federais brasileiras, constatou que apenas três disciplinas mobilizam bibliografias que abordam as avaliações institucionais e de sistemas, sem, com isso, fazer indicação desses temas como proposta das disciplinas. $\mathrm{O}$ autor salienta, ainda, a necessidade da discussão desses temas nas licenciaturas, enfatizando sua importância no contexto educacional e na futura prática docente.

Diante do exposto, esta pesquisa se insere no esforço de estudar o tema, mais especificamente, objetivando trazer contribuições para sua discussão nos países latino-americanos e ampliando o olhar para o modo como a formação de professores vem discutindo essas questões. Para isso, o objetivo é compreender como as avaliações institucionais e de sistemas são prescritas nos currículos (planos de disciplinas) dos cursos de formação de professores em Educação Física em oito países da América Latina.

\section{Teoria e método}

Esta pesquisa caracteriza-se como qualitativa e exploratória, assumindo a análise crítico-documental $(\mathrm{BLOCH}, 2001)$ como abordagem teórico-metodológica. Utiliza como fontes os currículos prescritos (SACRISTÁN, 2000) dos cursos de formação de professores em Educação Física de oito países da América Latina.

Ginzburg (1989) considera que perceber os indícios deixados pelas fontes revela as ações, os costumes, as reações e os pensamentos dos autores no momento em que determinado documento foi produzido. Nesse sentido, ao utilizarmos os planos de disciplinas ${ }^{1}$ de instituições de ensino latino-americanas como fonte de pesquisa, foi necessário estabelecermos uma análise que permitisse compreender os indícios das intencionalidades dos autores na proposição do tema avaliação. Buscamos, especificamente nesses documentos, compreender o ensino da avaliação para a formação do professor de Educação Física nesses países.

Para essa parte do estudo, inicialmente, analisamos 46 instituições de formação de professores de oito países latino-americanos que apresentam, em seus currículos, disciplinas específicas de avaliação educacional.

Após a definição das instituições, foi encaminhado um e-mail para cada uma com ofício explicando os objetivos e as finalidades da pesquisa, esclarecendo possíveis dúvidas e convidando-as para o estudo. Também solicitamos o envio do plano de disciplina. Esse processo ocorreu entre janeiro e abril de 2017. Dos 46 contatos realizados, 21 instituições enviaram os planos, conforme Quadro 1, no qual constam os países e os nomes das instituições com suas respectivas siglas. ${ }^{2}$ 
Quadro 1 - Relação de instituições e disciplinas

\begin{tabular}{|c|c|c|}
\hline País (8) & Universidade/Instituição (21) & Disciplina (22) \\
\hline \multirow{6}{*}{ Argentina (ARG) } & $\begin{array}{l}\text { Instituto Superior de Educación Física } \\
\text { "Federico Williams Dickens" (ISEFFD) }\end{array}$ & Evaluación aplicada \\
\hline & Universidad Maimónides (UM) & $\begin{array}{l}\text { Metodología de la evaluación y estadistica } \\
\text { aplicada }\end{array}$ \\
\hline & $\begin{array}{l}\text { Universidade Federal de Alagoas } \\
\text { (Ufal) }\end{array}$ & $\begin{array}{c}\text { Planejamento, currículo e avaliação da } \\
\text { aprendizagem }\end{array}$ \\
\hline & Universidade Federal do Ceará (UFC) & $\begin{array}{c}\text { Currículos, programas e avaliação em } \\
\text { Educação Física }\end{array}$ \\
\hline & Universidade Federal do Piauí (UFPI) & Avaliação da aprendizagem \\
\hline & $\begin{array}{l}\text { Universidade Federal Rural de } \\
\text { Pernambuco (UFRPE) }\end{array}$ & Avaliação em Educação Física escolar \\
\hline \multirow[t]{6}{*}{ Brasil (BRA) } & $\begin{array}{l}\text { Universidade Federal Fluminense } \\
\text { (UFF) }\end{array}$ & Avaliação em Educação Física \\
\hline & $\begin{array}{l}\text { Universidade Federal de Ouro Preto } \\
\text { (Ufop) }\end{array}$ & Avaliação escolar \\
\hline & $\begin{array}{l}\text { Universidade Federal de São Carlos } \\
\text { (UFSCar) }\end{array}$ & $\begin{array}{c}\text { Planejamento e avaliação em Educação Física } \\
\text { escolar }\end{array}$ \\
\hline & $\begin{array}{l}\text { Universidade Federal de Mato Grosso } \\
\text { do Sul (UFMS) }\end{array}$ & Avaliação em Educação Física escolar \\
\hline & Universidad de Concepción (UDEC) & Evaluación de aprendizaje \\
\hline & Universidad de Atacama (UDA) & $\begin{array}{l}\text { I) Metodología y evaluación de la Educación } \\
\text { Física } \\
\text { II) Evaluación educacional }\end{array}$ \\
\hline \multirow{3}{*}{ Chile (CHL) } & Universidad Andrés Bello (UNAB) & Currículum y evaluación \\
\hline & $\begin{array}{l}\text { Universidad Adventista de Chile } \\
\text { (UNACH) }\end{array}$ & Evaluación educacional \\
\hline & Universidad Católica de Oriente (UCO) & Teoría de la evaluación escolar \\
\hline Colômbia (COL) & $\begin{array}{l}\text { Institución Universitaria Centro de } \\
\text { Estudos Superiores Maria Goretti } \\
\text { (CESMAG) }\end{array}$ & Evaluación educativa \\
\hline Equador (ECU) & Universidad Nacional de Loja (UNL) & Evaluación curricular \\
\hline México (MEX) & $\begin{array}{l}\text { Universidad Autónoma de Baja } \\
\text { California (UABC) }\end{array}$ & Evaluación de la actividad física y deporte \\
\hline Uruguai (URY) & $\begin{array}{l}\text { Universidad de la República } \\
\text { (UDELAR) }\end{array}$ & Evaluación \\
\hline \multirow[t]{2}{*}{ Venezuela (VEN) } & $\begin{array}{l}\text { Universidad Nacional Experimental } \\
\text { de los Llanos Occidentales Ezequiel } \\
\text { Zamora (UNELLEZ) }\end{array}$ & Evaluación del aprendizaje \\
\hline & $\begin{array}{c}\text { Universidad Nacional Experimental de } \\
\text { Guayana (UNEG) }\end{array}$ & Evaluación de los aprendizajes \\
\hline
\end{tabular}

Fonte: autores. 
Como procedimento de análise das fontes, realizamos a leitura na íntegra desses documentos. Além disso, estabelecemos um cruzamento de dados entre a proposta das ementas com os objetivos e os conteúdos programáticos, cujos resultados foram as discussões centrais dessas disciplinas sobre a temática. No que se refere ao tratamento com as fontes, entendemos, assim como Ginzburg, que elas:

[...] não são nem janelas escancaradas, como acreditam os positivistas, nem muros que obstruem a visão, como pensam os céticos: no máximo poderíamos compará-las a espelhos deformantes. A análise da distorção específica de qualquer fonte implica já um elemento construtivo (2002, p. 44).

Inicialmente, dedicamos nossas análises aos 22 planos de disciplinas específicas de avaliação, referentes a 21 instituições de ensino de 8 países da América Latina, focalizando aquelas que apresentam discussões sobre avaliações institucionais ou de sistemas. Realizamos a leitura na íntegra desses documentos, explorando as ementas, os objetivos e os conteúdos programáticos.

\section{Avaliações institucionais e de sistemas nas disciplinas de avaliação da América Latina}

A leitura dos planos evidenciou que a discussão das temáticas se apresenta nas disciplinas que se propõem a discutir a avaliação de maneira mais ampla (educacional ou educativa). No Gráfico 1, expomos a distribuição do quantitativo de disciplinas que abordam as temáticas.

Gráfico 1 - Quantitativo de disciplinas com as temáticas

\section{Avaliação institucional e de sistemas}

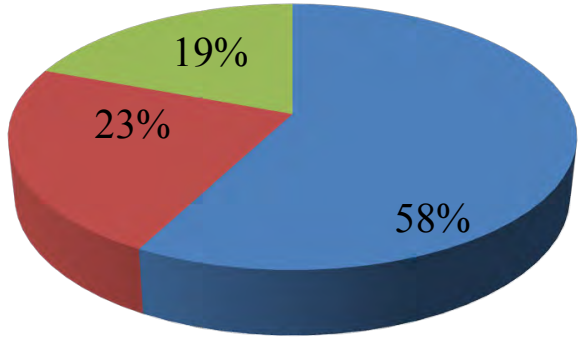

• Não apresenta

- Avaliação institucional

- Avaliação de sistemas

Fonte: autores. 
Das 22 disciplinas analisadas, 15 (58\%) não fazem menção à discussão das avaliações institucionais e de sistemas, são elas: UM/ARG, ISEFFD/ARG, Ufal/ BRA, UFC/BRA, UFPI/BRA, UFRPE/BRA, UFF/BRA, UFSCar/BRA, UFMS/BRA, UDEC/CHL, UDA I/CHL, UNAB/CHL, UABC/MEX, UDELAR/URY e UNEG/VEN.

Ao examinarmos os planos dessas disciplinas, percebemos indícios para justificar as ausências dessas discussões. A centralidade do que será abordado perpassa por seus títulos e/ou pelo conteúdo integral dos planos. Assim, observamos que as disciplinas da UNAB/CHL, da Ufal/BRA, da UFC/BRA e da UFSCar/BRA têm por eixo central os fundamentos do currículo e a avaliação da aprendizagem; a UM/ARG e o ISEFFD/ARG concentram suas discussões nas avaliações físicas e estatísticas aplicadas; a UNEG/VEN, a UDEC/CHL, a UFPI/BRA, a UFRPE/BRA, a UFF/BRA, a UFMS/BRA, a UDA I/CHL, a UABC/ MEX e a UDELAR/URY direcionam as suas disciplinas exclusivamente para avaliação da aprendizagem, sendo que as seis últimas relacionam o debate com a educação física.

A avaliação institucional é expressa especificamente em seis planos (Ufop/ BRA, UCO/COL, CESMAG/COL, UNACH/CHL, UNL/ECU e UNELLEZ/VEN), correspondendo a $23 \%$, de acordo com o Gráfico 1 . De maneira geral, vemos, nos planos, que apresentar essa discussão e estabelecer uma ligação entre a avaliação da aprendizagem e a avaliação institucional são os principais intuitos dessas disciplinas, conforme foi destacado pela CESMAG/COL na unidade de conteúdo Contextos de evaluación: aprendizaje, curricular e institucional - e em sua ementa:

[...] evaluación educativa no puede centrarse exclusivamente en la valoración de los resultados que alcanza la población estudiantil en sus aprendizajes, sino que se requiere establecer posturas sobre como avanzan los procesos en la parte curricular y en la organización institucional, que también son objeto de estudio e integran los contextos de trabajo de los futuros docentes.

Essa discussão evidencia-se também na UNELLEZ/VEN, que se propõe a discutir exclusivamente a avaliação da aprendizagem, porém destina uma unidade para estabelecer essa relação, e similarmente destaca em seu objetivo: "Analizar la relación de la evaluación institucional con la evaluación de los aprendizajes". Também nos conteúdos programáticos, a Ufop/BRA, a UNACH/CHL e a UNL/ECU destinam tópicos para abordar a definição de avaliação institucional, seus instrumentos, critérios, procedimentos e resultados. Já a UCO/COL traz este objetivo: "Informar sobre cómo se desarrollan los procesos de evaluación institucional y desempeño de los docentes en las instituciones educativas para que asuma actitudes propositivas en el momento de aplicarlas".

Para compreendermos como o ensino da avaliação institucional se configura nos países que envolvem esta pesquisa, realizamos uma busca por estudos que se 
debruçam sobre a temática. No entanto, os achados evidenciam que a centralidade nesses casos está na ideia de acreditación das instituições, tendo em vista se elas atendem aos requisitos previamente definidos por Comitês Interinstitucionais de Avaliação da Educação Superior, para realizar suas atividades (SANTOS, 2007).

Embora os planos de disciplina anunciem a relação entre avaliação institucional e avaliação da aprendizagem, notamos que sua articulação não ocorre de forma direta, pois a primeira está focalizada nos âmbitos estrutura física, corpo decente e projetos curriculares, enquanto a segunda envolve principalmente as apropriações dos alunos. Conforme salienta Santos:

[...] no se encuentra ningún trabajo empírico para sustentar la influencia de la información emanada de las evaluaciones con el aprendizaje institucional, pero se puede observar la existência de trabajos que buscan estudiar la influencia em los profesores, la misión de las instituciones y el mejoramiento de la cultura académica (2007, p. 13).

Nesse caso, o que predomina é a avaliação institucional na relação com a avaliação do ensino, ou seja, aquela que tem orientado o trabalho pedagógico do professor na construção do currículo, conforme sinalizado pela UCO/COL.

Com base nos fragmentos dos planos, observamos um movimento das disciplinas em apresentar, conceituar e relacionar os tipos de avaliação, preparando os futuros docentes para articular tais saberes em suas práticas pedagógicas. Por isso, consideram que a avaliação institucional tem por principal função proporcionar conhecimentos sobre a instituição e a comunidade interna, a fim de detectar suas potencialidades e fragilidades, transformando-se, assim, numa construção coletiva que beneficia, de forma complementar, todos os envolvidos no processo.

Especificamente no Brasil, Balzan e Dias Sobrinho (2000) destacam que a avaliação institucional começou a ser entendida e realizada desde 1980 e, no contexto das universidades brasileiras, a principal finalidade foi a transparência, ou seja, a exigência ética da prestação de contas à sociedade e o mecanismo de fortalecimento da instituição pública. De outro modo, ela também se configura em uma avaliação interna da escola, cujo objetivo é proporcionar conhecimentos sobre a instituição e a comunidade interna, de modo a detectar as suas fragilidades e potencialidades, tornando-se uma construção coletiva que beneficia, complementarmente, todos os envolvidos no processo (FREITAS, 2014).

Para Oliveira (2013), a abordagem do assunto na formação de professores deve ser priorizada, para que o conteúdo faça parte da grade curricular. Com essa ação ao longo do curso, os profissionais que chegassem ao campo profissional teriam maiores entendimento e contato com o tema e possivelmente o utilizariam em suas instituições escolares, contribuindo para um fazer docente mais qualificado por essa ação avaliativa contínua. 
Essa preocupação com a formação de professores também é levantada por Sordi e Ludke (2009) e Stieg (2016). Sordi e Ludke (2009) salientam que a aprendizagem da avaliação precisa ser elevada à condição estratégica nos processos de formação docente, sejam iniciais, sejam permanentes, pois um professor familiarizado com essas práticas ganha condição de bem ensinar e bem realizar a avaliação de/com seus estudantes. Os autores ressaltam, ainda, que a aprendizagem da avaliação institucional, ao tomar a escola por referência de análise da qualidade do ensino oferecido, constitui-se em mediação importante para macro e microabordagens dos processos de ensino.

Já para Stieg (2016), as contribuições dessa temática residem no fato de constituir um mecanismo de avaliação educacional mundialmente conhecido, com possibilidade de orientação e criação de novas maneiras de solucionar os desafios que surgem no contexto escolar e atravessam a prática pedagógica cotidiana, exigindo do professor a participação ativa nas políticas públicas que surgem das demandas educacionais.

Outra discussão tematizada nas disciplinas específicas é sobre a avaliação de sistemas, anunciada em cinco planos (Ufop/BRA, UDA II/CHL, UNACH/CHL, $\mathrm{UCO} / \mathrm{COL}$ e UNL/ECU), representando um percentual de 19\%, de acordo com o Gráfico 1. Estudiosos da avaliação de sistemas têm se dedicado à compreensão de suas características e de seus impactos na formação inicial de professores (AFONSO, 2000; SOUSA; LOPES, 2010; ESTEBAN; FETZNER, 2015), visto que o exame tem sido entendido como "[...] uma das peças do sistema" (AFONSO, 2000, p. 30).

No que concerne à avaliação de sistemas na Ufop/BRA, além de anunciar na ementa da disciplina o tema, destina-se uma unidade de estudos aos usos e às críticas à avaliação de sistemas, estadual, nacional e internacional (Sistema de Avaliação da Educação Básica - Saeb, Prova Brasil, Provinha Brasil, Sistema Mineiro de Avaliação da Educação Pública - Simave e Pisa). A disciplina da UCO/COL, em sua ementa, problematiza a importância da temática no curso de formação de professores: "La evaluación es una de los componentes del modelo pedagógico de la institución educativa que debe ser objeto de especial atención por parte de las instituciones e forman los maestros de las nuevas generaciones". E utiliza como argumento que, num contexto mais amplo, a temática é complexa, envolve fatores como a aprendizagem dos estudantes, o desempenho dos docentes, os processos institucionais e as avaliações internacionais. Assim sendo, "el futuro maestro debe tener una formación en cada uno de estos componentes para poder responder de manera efectiva a situaciones que se le presentan en su práctica diária". Sobre a avaliação de sistemas, direciona uma unidade para discutir as provas "massivas" que se realizam na Colômbia, seus componentes e as competências que se avaliam 
em cada uma delas. Propõe, ainda, que o professor em formação conheça a estrutura das provas internacionais de que o país tem participado nos últimos anos.

A UNL/ECU propõe como objetivo da disciplina: "proporcionar elementos teóricos metodológicos para evaluar los diferentes procesos del sistema educativo nacional". Para isso, apresenta uma unidade específica que aborda os âmbitos básicos da avaliação educacional, tais como: aprendizagem dos estudantes, desempenho docente, de programas, de centros educativos, institucional e de sistemas educativos. Já a UNACH/CHL busca caracterizar a avaliação em nível de sistema educativo, escola e aula, para que o aluno em formação tenha micro e macrovisão da temática, bem como sua articulação.

Historicamente, no Brasil, não é a avaliação de sistemas que se torna a grande referência, como acontece em alguns países, como a Inglaterra, a Escócia, os Estados Unidos da América (HARLEN, 2006, BLACK; WILIAM, 1998) e Portugal (FERNANDES, 2007), que têm compreendido que a avaliação se materializa na aprovação e na certificação, nas quais se atribui ao mecanismo regulatório externo a tarefa de avaliar.

A disciplina II da UDA/CHL articula a avaliação da aprendizagem com a discussão da avaliação de sistemas, fomentando questionamentos, como: ¿Qué podemos aprender y cómo podemos utilizar las evaluaciones externas nacionales e internacionales? Para fundamentar esse debate, aborda-se a avaliação de sistemas nos contextos tanto chileno quanto internacional, em referência ao Pisa.

O tema da avaliação surge com força, devido à importância que as avaliações externas internacionais e padronizadas adquiriram nas últimas décadas: uma questão que é acompanhada por níveis mais altos ou mais baixos de adesão em cada país onde elas são implementadas. Ravela et al. (2008) salientam que os anos de 1990 foram prolíficos em matéria de avaliação estandardizada, não só na América Latina, mas em quase todo o mundo.

Com diferentes matrizes teóricas (da filosofia, da psicologia da educação, da psicometria) e com diferentes nomenclaturas ("avaliação de programas”, nos Estados Unidos da América; "avaliação de sistemas educacionais", na Inglaterra e no País de Gales; "avaliação sistêmica”, na França; "avaliações do sistema”, em Portugal; e "avaliação em larga escala", no Chile e no Brasil), essa temática tem em comum a ideia dos standardized exams (exames estandardizados), ou seja, avaliações somativas que têm por objetivo levantar dados sobre o sistema educacional dos Estados, para a elaboração de políticas educacionais, para que tentem determinar até onde os objetivos educacionais estão sendo realmente alcançados, visando racionalizar e padronizar a qualidade do sistema educativo. 
Com esse propósito, na América Latina, a UNESCO/OREALC criou o Laboratório Latinoamericano de Evaluación de la Calidad de la Educación (LLECE), realizando um primeiro estudo regional em educação primária entre 1995 e 1998. Ravela et al. (2008) destacam, ainda, que, para além do estudo realizado, o LLECE se transformou em uma importante rede de intercâmbio e trabalho cooperativo entre as unidades de avaliação dos países membros.

Atualmente, o LLECE desenvolveu a terceira edição do Estudo Regional Comparativo e Explicativo, envolvendo a participação de estudantes de 3. e 6. ${ }^{\circ}$ anos de escolas primárias, nas áreas de Matemática, Linguagem (leitura e escrita) e Ciências Naturais. $\mathrm{O}$ estudo avalia o desempenho dos alunos em relação aos elementos comuns dos currículos escolares da região, focados nos padrões de cada país, e inclui aplicação de questionários contextuais, para compreender as circunstâncias em que a aprendizagem ocorre. São contextos socioeconômicos, familiares e pessoais, bem como políticas e processos educacionais de dinâmica escolar.

Já no fim dos anos 1990, a OCDE deu forma ao Pisa, uma rede mundial de avaliação de desempenho escolar, realizado pela primeira vez em 2000 e repetido a cada três anos. A avaliação envolve Leitura, Matemática e Ciências e é aplicada a estudantes de 15 anos (pressupõe-se o término da escolaridade básica obrigatória na maioria dos países).

Outro sistema incorporado por países da América Latina foi o IEA, que realiza estudos comparativos em larga escala das realidades educacionais e se concentra em assuntos relacionados às áreas de Matemática, Ciências, Leitura, Alfabetização, Educação Cívica e Cidadania. Diante desse contexto, identificamos que não há, nessas avaliações, a presença da Educação Física como componente curricular a ser avaliado.

Segundo Ravela et al. (2008), entre 1992 e 2002, mais de 120 países participaram de pelo menos uma avaliação regional ou internacional. E, nesses contextos, foram criados também os sistemas nacionais de avaliação e/ou implementados estudos pontuais em toda região.

Com base na pesquisa de Duro (2015), podemos evidenciar os principais sistemas nacionais da América Latina, seu início e as áreas que são avaliadas. No Brasil, iniciou, em 1990, o Saeb, com o objetivo de diagnosticar o sistema educacional brasileiro, envolvendo Língua Portuguesa, Alfabetização e Matemática. Além disso, desde 1998, realiza-se o Exame Nacional do Ensino Médio (Enem), envolvendo os conteúdos de Ciências Humanas, Ciências da Natureza, Matemática, Linguagens e Códigos e suas Tecnologias e, a partir de 2009, Educação Física. Já a Colômbia criou, em 1991, as Pruebas Saber, para avaliar as competências em Linguagem e Matemática, com inserção das áreas das Ciências Naturais e Competên- 
cias Cidadãs em 2012. A Argentina, desde 1993, por meio do Operativo Nacional de Evaluación (ONE), avalia o desempenho dos estudantes em Língua, Matemática, Ciências Naturais e Ciências Sociais. O Chile, desde 1998, utiliza o Sistema de Medición de la Calidad de la Educación (Simce), para avaliar o domínio dos conteúdos e habilidades do currículo vigente em Linguagem e Comunicação (leitura e escrita), Matemática, Ciências Naturais, História, Geografia, Ciências Sociais, Inglês e Educação Física. No México, é realizada anualmente, desde 2006, a Evaluación Nacional de Logros Académicos en Centros Escolares (Enlace), para conhecer o nível de desempenho nas matérias de Espanhol e Matemática, incluindo, a partir de 2008, as matérias de Ciências Naturais, Formação Cívica e Ética, História, Geografia. O Uruguai iniciou seu desenvolvimento em 2006, utilizando o Sistema de evaluación del aprendizaje (SEA), tendo por diferencial sua aplicação on-line, envolvendo conteúdos de Matemática, Leitura e Ciências Naturais. O Equador, em 2008, elaborou as provas SER Ecuador, cuja finalidade é avaliar as competências em Linguagem e Comunicação, Matemática, Estudos Sociais e Ciências Naturais.

Esse panorama evidencia dois movimentos: as concepções de conhecimento e de currículo. O primeiro revela que, apenas no Brasil e no Chile, a Educação Física aparece como área de conhecimento a ser avaliada com outros componentes curriculares. De acordo com Hopfenbeck e Baird (2014), as concepções de aprendizagem presentes nos testes internacionais estão enraizadas no modelo cognitivo de aprendizagem. Em relação à concepção de currículo, percebemos que eles estão pautados nas habilidades e competências que ganham evidência no cenário internacional com autores como Cesar Coll e Antoni Zabala.

Quando analisamos essas avaliações nacionais com as avaliações em nível internacional (Pisa, por exemplo), percebemos que elas expressam um movimento de alinhamento do conhecimento a ser avaliado, ou seja, as avaliações nacionais funcionam como uma preparação para as avalições internacionais, conforme evidenciado no estudo de Hopfenbeck e Baird (2014). Diante desse contexto, observamos que os sistemas nacionais e internacionais de avaliação diferem nos países nos seguintes aspectos: nomenclatura; período em que se aplicam (anual, trienal, quadrienal); público-alvo (grau básico e/ou grau médio); e áreas abordadas (Linguagem, Ciências Naturais, Sociais). Evidencia-se, assim, a preocupação das disciplinas em possibilitar ao professor em formação o conhecimento das estruturas das provas nacionais e internacionais de que o país tem participado nos últimos anos.

Após a apresentação dos principais sistemas de avaliações externas nacionais e internacionais, presentes nos oito países estudados, é importante destacar que tais sistemas não são vistos da mesma maneira por educadores e estudiosos da educação, havendo duas visões divergentes acerca do tema, já que, como todo pro- 
grama de caráter abrangente, as avaliações de sistemas voltadas para a educação também são passíveis de críticas e elogios.

As principais críticas tecidas às avaliações externas referem-se à sua utilização para a responsabilização da escola e, consequentemente, do professor e dos alunos (ARAÚJO; FERNANDES, 2009; ALTMANN, 2002), visto que somente os dados quantitativos dos exames, apresentados pelo governo, não podem ser a única referência sobre o nível de aprendizagem dos alunos, pois, vistos por si mesmos, eles não são suficientes para uma análise sobre os efeitos da expansão do ensino nem para a criação de mecanismos de hierarquização das escolas.

Casassus (2009), corroborando esse pensamento, põe em xeque a validade e a efetividade das avaliações externas na melhoria da educação nos países da América Latina, tendo em vista que as provas estandardizadas, como sistemas de avaliação centralizados, não informam a qualidade da educação, e sim promovem a desigualdade. $\mathrm{O}$ autor enfatiza, ainda, que uma das razões primordiais desse fracasso foi nunca ter dito o que se entende por qualidade da educação, uma vez que, em vinte anos, os resultados obtidos não apontam progressos, mas retrocessos em muitos países da América Latina, ao passo que a segmentação social e a desigualdade foram fortalecidas.

De outro modo, Machado (2012) considera esse sistema de avaliação favorável e pontua que os processos avaliativos externos devem proporcionar revisões necessárias do trabalho desenvolvido nas escolas, de modo que seus resultados sejam utilizados na análise coletiva da realidade escolar e no direcionamento de ações e alternativas para enfrentar as dificuldades vivenciadas no ensino e na aprendizagem.

Compreendemos que essas avaliações externas acabam estabelecendo a pauta da política educacional em cada país, utilizadas para justificar as reformas educacionais. Conforme salientam Hopfenbeck e Baird (2014), devido ao seu financiamento governamental, os resultados dos testes internacionais podem ser usados para legitimar políticas. Nessa mesma direção, em contexto brasileiro, Esteban e Fetzner observam que as avaliações externas têm se ampliado com testes estandardizados, que se expressam na forma "[...] de mecanismos de controle e redução dos processos de ensino e de aprendizagem desde o início da vida escolar propostos pela Provinha Brasil, e pela instituição de exames de larga escala para sistemas estaduais ou municipais" (2015, p. 82). As autoras também destacam que as avaliações de sistemas têm apresentado baixo desempenho de aprendizagem e de conhecimentos válidos, caracterizando-se mais como indicadores de desigualdade, reduzindo-se à apresentação dos resultados que precisam ser corrigidos. 
Hein e Taut, ao analisarem o uso de informações avaliativas externas com fins formativos no contexto chileno, destacam que "La introducción de un sistema de evaluación externa puede enfrentar resistencias que pueden frenar su uso, particularmente en el caso de los docentes" (2010, p. 164). Mediante a afirmação, os autores citam quatro fatores que podem dificultar o uso dessa avaliação no ambiente educacional: problemas de compreensão relativa ao uso de dados quantitativos; foco exclusivo em uma avaliação externa ou interna; baixa capacidade organizacional; e cultura de avaliação. Corroborando os autores, Duro salienta que:

Es común constatar que en las instancias de diseño de evaluaciones educativas internacionales o nacionales no siempre se integran a docentes que estén ejerciendo su profesión en las aulas. Sumado a ello, en ocasiones la información que se difunde alcanza niveles de complejidad que solo aquellos que están en el tema evaluativo alcanzan comprensión cabal de los múltiples significados que de allí se derivan. Se adiciona que el uso y análisis de información compleja, no suele formar parte de los procesos de formación docente, vieja deuda que interfiere en un mejor aprovechamiento de la información. La ausencia de participación de los actores que conforman el proceso educativo aunado a modelos evaluativos cada vez más complejos, en lugar de fortalecer cultura evaluativa en las escuelas, ha provocado reacciones no siempre favorables al hecho evaluativo (2015, p. 3).

Nevo (2001), ao investigar a relação das avaliações externa e interna no ambiente escolar, destaca, como ponto positivo, que ela pode aumentar o envolvimento dos docentes nos processos de tomada de decisão fora da sala de aula, estabelecer colegialidade e colaboração entre os professores, além de servir como meio de promover reflexão, sendo esses aspectos fundamentais para o desenvolvimento da profissionalidade docente. Além disso, ressalta que a avaliação interna pode beneficiar-se da avaliação externa, pelo menos de três maneiras: estimular a avaliação interna, ampliar seu escopo e legitimar sua validade.

Ao partir do questionamento: ¿qué conocimientos son necesarios para que los profesores exploren el potencial de los resultados de las evaluaciones externas en la perspectiva de ampliación de la calidad de la enseñanza-aprendizaje en las escuelas?, o estudo de Alavarse, Machado, Arcas (2017) objetivou cotejar os resultados da avaliação externa (Prova São Paulo) com os resultados das avaliações internas feitas pelos professores. Como resultado, os autores evidenciam que as provas externas são organizadas com itens elaborados com base em uma matriz que expressa os objetos de avaliação. E, nesse sentido, é importante conhecer, estudar e esmiuçar essas matrizes que fundamentam os temas e assuntos das provas padronizadas, para que o professor possa cotejá-los com o currículo adotado pela escola e utilizado por ele na sala de aula. Destacam, ainda, que os professores precisam apropriar-se de conhecimento sobre o contexto, os pressupostos e o papel das 
avaliações externas, bem como o seu potencial de uso dos resultados no cotidiano da sala de aula.

Esses estudos demonstram a importância do professor nesse processo, sendo ele um dos agentes de mediação entre a avaliação externa e a interna da escola. Evidenciam também que, assim como ocorre no contexto norueguês (BAIRD, 2014), as avaliações internacionais são essencialmente projetadas para medir sistemas educacionais e, consequentemente, sua conexão com a aprendizagem dos alunos é menos direta do que a de outras avaliações realizadas pelos professores. No entanto, seu impacto sobre a definição de aprendizagem nos níveis governamentais é cada vez mais evidente.

É preciso levar em consideração que não basta analisar o uso que se tem feito das avaliações internacionais, deve-se também discutir sua função, pois não se faz a avaliação de um sistema educativo sem uma avaliação que dê conta disso. Além disso, é necessário construir uma lógica de avaliação que leve em consideração as diferentes esferas do campo educacional, os desdobramentos dos diferentes tipos de avaliação e a concepção que se assume para ler os dados e orientar uma política educacional a partir disso.

Ao abordarmos a discussão das avaliações institucional e de sistemas, é preciso reconhecer que cada uma tem um contexto, fundamentos, objetivos e resultados específicos (em âmbito local ou geral), mas que, no contexto educacional, esses dois níveis, somados à avaliação da aprendizagem, articulam-se e complementam-se, pois:

[...] a avaliação de sistemas é um instrumento importante para monitoração das políticas públicas e seus resultados devem ser encaminhados, como subsídio, à escola para que, dentro de um processo de avaliação institucional, ela possa consumir estes dados, validá-los e encontrar formas de melhoria. A avaliação institucional fará a mediação e dará, então, subsídios para a avaliação de sala de aula, conduzida pelo professor (FREITAS, 2014, p. 65 , grifo do autor).

Dessa maneira, com base nos apontamentos de Freitas (2014) e nos dados apresentados, destacamos que essas temáticas precisam ser mais problematizadas nos cursos de formação de professores, para que o aluno compreenda a amplitude que a avaliação assume no contexto escolar e possa mobilizá-la no seu trabalho pedagógico. 


\section{Considerações finais}

Objetivou-se, nesta pesquisa, compreender como as avaliações institucional e de sistemas são prescritas nos currículos dos cursos de formação de professores em Educação Física em oito países da América Latina. Isso permitiu identificar que, de um total de 22 disciplinas específicas, as temáticas avaliação institucional e avaliação de sistemas são abordadas em seis e cinco planos, respectivamente. Sobre a avaliação institucional, são abordados: definição, instrumentos, critérios, procedimentos e resultados, entendendo-a como uma importante ferramenta coletiva, ao proporcionar conhecimentos sobre a instituição e a comunidade interna e detectando suas potencialidades e fragilidades. Já a avaliação de sistemas é indicada em cinco planos, no intuito de apresentar as provas de larga escala nacionais e internacionais, abordando os componentes e as estruturas de ambas.

A respeito dos exames nacionais, cada país desenvolve e aplica suas provas, tendo como ponto comum o intuito de realizar um levantamento de dados sobre o sistema educacional dos estados para a elaboração de políticas educacionais, visando acompanhar, racionalizar e padronizar a qualidade do sistema educativo. Já como aspectos divergentes, destacam-se as nomenclaturas, os períodos em que são aplicadas (anual, trienal, quadrienal), o público-alvo (grau básico e/ou médio), o tipo de aplicação (prova escrita impressa ou on-line) e as áreas abordadas (Linguagem, Matemática, Ciências Naturais, etc.).

Sobre as áreas abordadas nessas provas, dos países presentes neste estudo, em dois casos (Brasil e Chile) há a presença da Educação Física no exame nacional. Mesmo com essa constatação e com a escassez de estudos que articulam essas temáticas, ressalta-se a importância de haver um debate amplo e aprofundado sobre esse tema na formação de professores, que estabeleça relação com a especificidade da área.

Outro ponto a ser destacado nas disciplinas é que, de maneira geral, elas demonstram preocupação em estabelecer relação entre as diferentes modalidades de avaliação (sistema educativo, escola e aula), para que o aluno em formação tenha uma visão macro e micro da temática, bem como de sua articulação.

Por fim, as análises projetadas neste estudo apontam a necessidade de novas pesquisas que aprofundem as bibliografias usadas nessas disciplinas, para investigar quais matrizes teóricas e concepções de avaliação são utilizadas. Além disso, assinala-se para a necessidade de compreender o modo como os professores propõem o ensino da avaliação nessas instituições. 


\section{Notas}

1 Entendemos por plano de disciplina um tipo de planejamento que busca a previsão global para as atividades de uma determinada disciplina durante o período do curso, geralmente organizado em dados de identificação da disciplina, ementa, objetivos, conteúdo programático, metodologia, avaliação e bibliografia básica e complementar da disciplina.

2 Assumimos as siglas no intuito de padronizar a abreviação das instituições, tomando como referência o modo como algumas o fazem em seu endereço eletrônico.

\section{Referências}

AFONSO, A. J. Avaliação educacional: regulação e emancipação. 2. ed. São Paulo: Cortez, 2000.

ALAVARSE, O. M.; MACHADO, C.; ARCAS, P. H. Avaliação externa e qualidade da educação: formação docente em questão. Revista Diálogo Educacional, Curitiba, v. 17, n. 54, p. 1353-1375, jul./set. 2017.

ALTMANN, H. Influências do Banco Mundial no projeto educacional brasileiro. Educação e Pesquisa, São Paulo, v. 28, n. 1, p. 77-89, jan./jun. 2002.

ARAÚJO, G. C.; FERNANDES, C. F. R. Qualidade do ensino e avaliações em larga escala no Brasil: os desafios do processo e do sucesso educativo na garantia do direito à educação. Revista Iberoamericana de Evaluación Educativa, v. 2, n. 2, p. 125-140, 2009. Disponível em: <https:// revistas.uam.es/index.php/riee/article/view/4562/4994>. Acesso em: 19 abr. 2018.

BAIRD, J. A. Valuable learning. In: BAIRD, J. et al. Assessment and Learning: State of the Field Review. Oslo: Knowledge Center for Education, 2014. p. 20-29.

BALZAN, C. N.; DIAS SOBRINHO, J. (Org.). Avaliação institucional - teoria e experiências. São Paulo: Cortez, 2000.

BLACK, P.; WILIAM, D. Assessment and classroom learning. Assessment in Education: Principles, Policy \& Practice, Princeton, v. 5, n. 1, p. 7-74, 1998.

BLOCH, M. L. B. Apologia da história ou o ofício do historiador. Jorge Zahar: Rio de Janeiro, 2001.

CASASSUS, J. Uma nota crítica sobre a avaliação estandardizada: a perda de qualidade e a segmentação social. Sísifo - Revista de Ciências da Educação, n. 9, p. 71-78, maio/ago. 2009.

CERÓN, M. S.; CRUZ, F. M. S. C. Las evaluaciones estandarizadas: sus efectos entres países latinoamericanos. Revista Latinoamericana de Estudios Educativos, México, v. 43, n. 1, p. 97-124, 2013.

DURO, E. La autoevaluación educativa en Argentina y la región de LAC. In: IV CONFERENCIA RELAC, 2015, Lima. Ponencias... Lima, 2015. Disponível em: <http://www.ceadel.org.ar/IACEunicef/Archivos/Ponencia_EDuro_IVConf_ReLAC_Lima.pdf>. Acesso em: 03 abr. 2018.

ESTEBAN, M. T.; FETZNER, A. R. A redução da escola: a avaliação externa e o aprisionamento curricular. Educar em Revista, Edição especial, n. 1, p. 75-92, 2015. 
FERNANDES, D. A avaliação das aprendizagens no sistema educativo português. Educação $e$ Pesquisa, São Paulo, v. 33, n. 3, p. 581-600, set./dez. 2007.

FREITAS, L. C. Avaliação educacional: caminhando pela contramão. 6. ed. Vozes: Petrópolis, 2014.

GAJARDO, M. Reformas educativas en América Latina. Balance de una década. Santiago de Chile: PREAL, 1999. Disponível em: <http://www.opech.cl/bibliografico/calidad_equidad/Reformas_educativas_balance_de_decada_PREAL.pdf >. Acesso em: 27 abr. 2018.

GINZBURG, C. Mitos, emblemas, sinais: morfologia e história. São Paulo: Companhia das Letras, 1989.

Relações de força: histórica, retórica, prova. Tradução de Jônatas Batista Neto. São Paulo: Companhia das Letras, 2002.

HARLEN, W. On the relationship between assessment for formative and summative purposes. In: GARDNER, J. (Ed.). Assessment and learning. London: Sage, 2006. p. 103-118.

HEIN, A.; TAUT, S. El uso de información evaluativa externa con fines formativos en establecimientos educacionales chilenos. Revista Iberoamericana de Evaluación Educativa, Madrid, v. 3, n. 2, p. 160-181, mayo 2010 .

HOPFENBECK, T. N.; BAIRD, J. A. International tests. In: BAIRD, J. et al. Assessment and Learning: State of the Field Review. Oslo: Knowledge Center for Education, 2014. p. 60-77.

MACHADO, C. Avaliação externa e gestão escolar: reflexões sobre usos dos resultados. Revista @mbienteeducação, São Paulo, v. 5, n. 1, p. 70-82, jan./jun. 2012.

MURILLO, F. J.; ROMÁN, M. Retos en la evaluación de la calidad de la educación en américa latina. Revista Iberoamericana de Educación, Madrid, n. 53, p. 97-120, 2010.

NEVO, D. School evaluation: internal or external? Estudies in Educational Evaluation, Amsterdam, v. 27, p. 95-106, 2001.

OLIVEIRA, C. P. Avaliação institucional na educação básica: limitações e possibilidades. 2013. 178 f. Dissertação (Mestrado em Educação) - Universidade do Estado da Bahia, Salvador, 2013.

OLIVEIRA, R. P. Reformas educativas no Brasil na década de 90. In: OLIVEIRA, R. P.; CATANI, A. M. (Ed.). Reformas educacionais em Portugal e no Brasil. Belo Horizonte: Autêntica, 2000. p. 77-94.

RAVELA, P. et al. La evaluación externa en seis países de américa latina: balances y retos. Buenos Aires: Bonaventuriana, 2008. Disponível em: <https://issuu.com/hansmejiaguerrero/docs/ libro_fin>. Acesso em: 16 maio 2018.

SACRISTÁN, J. G. O currículo: uma reflexão sobre a prática. Porto Alegre: Artmed, 2000.

SANTOS, L. L. Evaluación institucional y factores de cambio: la perecepción de los académicos de tres universidades del noroeste de México. Revista de la Educación Superior, Ciudad de México, v. 36 , n. 144 , p. $7-22$, oct./dic. 2007.

SORDI, M. R. L.; LUDKE, M. Da avaliação da aprendizagem à avaliação institucional: aprendizagens necessárias. Avaliação, Campinas, v. 14, n. 2, p. 253-266, jul. 2009. 
SOUSA, S. Z.; LOPES, V. V. Avaliação nas políticas atuais reitera desigualdades. Revista Edusp, São Paulo, v. 1, p. 53-59, jan. 2010.

STIEG, R. Formação inicial em educação física nas universidades federais brasileiras: fundamentos teóricos das disciplinas de avaliação e práticas de leitura. 2016. 140 f. Dissertação (Mestrado em Educação Física) - Universidade Federal do Espírito Santo, Vitória, 2016. 